\title{
Correction to: Optimization of Cold Spray Deposition of High-Density Polyethylene Powders
}

Trenton P. Bush ${ }^{1} \cdot$ Zahra Zhalkhali $^{1} \cdot$ Victor Champagne $^{2} \cdot$ David P. Schmidt $^{1}$. Jonathan P. Rothstein ${ }^{1}$

Published online: 19 December 2017

(C) ASM International 2017

Correction to: J Therm Spray Tech (2017)

\section{6:1548-1564}

DOI 10.1007/s11666-017-0627-5

We regret that the original article contained an incorrect initial for the first listed author. The name should have been published to read: Trenton P. Bush.

The original article can be found online at https://doi.org/10.1007/s11666-017-0627-5.

Jonathan P. Rothstein

rothstein@ecs.umass.edu

1 Department of Mechanical and Industrial Engineering, University of Massachusetts, Amherst, MA 01003, USA

2 U.S. Army Research Laboratory, Weapons and Materials Research Directorate, Aberdeen Proving Ground, Aberdeen, MD 21005, USA 